\title{
Aplicação da termografia na identificação de infiltrações e tubulações para condução de água fria e água quente embutidas em alvenaria
}

\author{
Application of thermography in the identification of infiltractions and pipes for conducting cold \\ water and hot water embedded in masonry
}

Aplicación de la termografía en la identificación de infiltracciones y tuberías de conducción de agua fría y agua caliente empotradas en mampostería

\author{
Roberto Lopes Burity Filho \\ ORCID: https://orcid.org/0000-0001-9837-418X \\ Universidade Federal da Paraíba, Brasil \\ E-mail: binhoburity@gmail.com \\ Ysa Helena Diniz Morais de Luna \\ ORCID: https://orcid.org/0000-0002-0192-3603 \\ Universidade Federal da Paraíba, Brasil \\ E-mail: ysaluna@gmail.com \\ Marçal Rosas Florentino Lima Filho \\ ORCID: https://orcid.org/0000-0003-4821-8458 \\ Universidade Federal da Paraíba, Brasil \\ E-mail: marcal@cear.ufpb.br \\ Gilson Barbosa Athayde Júnior \\ ORCID: https://orcid.org/0000-0003-2815-7600 \\ Universidade Federal da Paraíba, Brasil \\ E-mail: gilson@ct.ufpb.br
}

\begin{abstract}
Resumo
A análise de obras civis para detecção de patologias e anomalias tem empregado cada vez mais a metodologia da termografia infravermelha (IRT), permitindo ao olho humano a "leitura" da temperatura dos objetos. Dada importância de se realizar a identificação de tubulações embutidas em alvenaria, quando não mais se possui os projetos hidráulicos e sanitários, o objetivo do presente trabalho foi de aplicar a metodologia ITR para: identificar infiltrações não perceptíveis e investigar o seu uso para detecção de tubulações de água fria e quente embutidas. Com relação a identificação de infiltrações, os resultados confirmaram a adequação da metodologia para tal finalidade, inclusive para detecção de infiltrações não perceptíveis. No entanto, para identificação de tubulações hidráulicas embutidas nas paredes a metodologia apresentou a limitação ao ser executada em parede de revestimento cerâmico, que impede a captação da temperatura da parede. Na investigação em paredes de revestimento simples a IRT não se mostrou eficiente para identificação de tubulações de água fria, contudo, sinalizou potencialidade da termografia para detecção de tubulações de água quente, uma vez que ocorre elevado gradiente de temperatura entre a tubulação e a parede.
\end{abstract}

Palavras-chave: Termografia infravermelha; Elementos construtivos; Tubulações; Infiltrações.

\begin{abstract}
The methodology of infrared thermography (IRT) has been applied to the analysis of civil constructions to detect pathologies and anomalies, allowing human eye to "read" the temperature of objects. Given the importance of carrying out the identification of pipes embedded in masonry, in cases when hydraulic and sanitary projects does not exist anymore, the objective of the present work was to apply the IRT methodology to: identify non perceptible infiltrations and to investigate its use for inlaid pipe's detection of cold and hot water. Regarding the identification of infiltrations, the results confirmed the adequacy of the methodology for this purpose, including for the detection of non-perceptible infiltrations. However, for the identification of hydraulic pipes embedded in the walls, the methodology presented the limitation when being executed in a ceramic wall, which blocks the capture of the wall temperature. In the investigation of simple cladding walls, the IRT was not efficient to identify cold water pipes, however, it indicates the potential of thermography for the detection of hot water pipes, since there is high temperature gradient between the pipe and the wall.
\end{abstract}

Keywords: Infrared thermography; Construction elements; Pipes; Infiltrations. 


\section{Resumen}

El análisis de obra civil para detectar patologías y anomalías ha utilizado cada vez más la metodología de la termografía infrarroja (IRT), que permite al ojo humano "leer" la temperatura de los objetos. Dada la importancia de realizar la identificación de tubería incrustada en albañilería, cuando ya no contamos con los proyectos hidráulicos y sanitarios, el objetivo del presente trabajo fue aplicar la metodología ITR para: identificar fugas no perceptibles e investigar su uso para la detección de tubería de agua fría y caliente incrustada. En cuanto a la identificación de infiltraciones, los resultados confirmaron la adecuación de la metodología para este fin, incluida la detección de infiltraciones no perceptibles. Sin embargo, para la identificación de tuberías hidráulicas incrustada en las paredes, la metodología presentó una limitación cuando se realizó en una parede de revestimiento de cerámica, que evita la captura de la temperatura de la pared. En la investigación de paredes de revestimiento simple, el IRT no fue eficiente para identificar tuberías de agua fría, sin embargo, señaló el potencial de la termografía para detectar tuberías de agua caliente, ya que existe un gradiente de temperatura elevado entre la tubería y la pared.

Palabras clave: Termografía infrarroja; Elementos constructivos; Tuberías; Infiltraciones.

\section{Introdução}

A termografia infravermelha (Infrared thermography, IRT) é um método não invasivo e não destrutivo, que efetua a aquisição e a análise de dados de dispositivos de imagem térmica (Barreira et al., 2016). Por meio de uma câmera termográfica é possível realizar a detecção da radiação emitida pelo objeto em análise e convertê-la em uma imagem bidimensional (Santos, 2012). Silva (2007) descreve dois tipos de termografia: a termografia passiva que captura imagens térmicas de determinado objeto aquecido pelo próprio processo, e a termografia ativa que por sua vez efetua a análise de um objeto aquecido artificialmente. Sendo assim, a IRT permite que os seres humanos literalmente observem as imagens térmicas geradas pelos corpos em temperaturas próximas à do ambiente.

Este método apresenta vantagens para aplicação em inspeção, pois pode conseguir resultados rápidos sem a necessidade de contato físico com o objeto analisado e detectar danos não visíveis a olho nu, apresentando resultados em tempo real (Santos et al., 2019), possibilitando também visualização de objetos em ambientes perigosos, com difícil acesso, ou ainda como cita Almeida et al. (2020) em grandes alturas mediante a aplicação do IRT integrada a um drone. No entanto, Rocha e Póvoas (2017) apresentam algumas limitações da técnica quanto à profundidade de detecção de defeitos, à influência das condições ambientais e o horário de coleta de dados.

Barreira (2004) aponta aplicações da IRT em diversas áreas da ciência, tais como: na medicina para exames nãoinvasivos aos tecidos e fluido; na astronomia possibilitando a observação à longa distância; nos mapeamentos meteorológicos; na segurança e vigilância como a utilização de imagens noturnas, ou em condições de má visibilidade; na indústria é utilizada para manutenção de sistemas mecânicos; no monitoramento ambiental para controlar o desmatamento e propagação de incêndios, dentre outros.

A técnica da IRT tem atraído a atenção do meio técnico-científico, podendo-se citar a publicação em 27 de fevereiro de 2020 da Norma Brasileira $n^{\circ} 16818$, intitulada de "Ensaios não destrutivos - Termografia infravermelha - Procedimentos para aplicações do método da termografia infravermelha" (ABNT, 2020) por parte da Associação Brasileira de Normas Técnicas (ABNT), tornando assim a aplicação da metodologia padronizada.

O emprego da IRT é um método bastante utilizado na inspeção de obras civis, baseando-se na existência de incoerências nos padrões de temperatura dos elementos da construção (Kersul, 2015), e segundo Santos et al. (2019) e Garrido et al. (2018) vem apresentando cada vez mais aplicações a construção civil tais como: estudo de manifestações patológicas em fachadas, estudo do desempenho térmico de edificações, inspeção de pontes, estrutura do asfalto, materiais metálicos, estudo de manifestações patológicas e fenômenos associados a umidade em edificações, infiltrações em paredes e coberturas, entre outros.

A presença de umidade em uma edificação geralmente é detectada após o surgimento de forma visível das manifestações patológicas como eflorescência, destacamento, ou presença de bolor, sendo esses casos indesejáveis (Edis et al., 
2014) e, normalmente, a avaliação dos problemas relacionados à umidade e de seu teor é realizada por métodos destrutivos. No entanto, na área de diagnóstico de manifestações patológicas é priorizada a utilização de ferramentas não destrutivas devido ao inconveniente causado por técnicas destrutivas, principalmente nas construções habitadas (Freitas et al., 2014).

Segundo Barreira et al. (2016) a detecção da presença de água em edificações é viável pela termografia devido a três fenômenos físicos: o resfriamento evaporativo na área úmida, a resistência térmica diminuída e pelo aumento da capacidade de armazenamento de calor do material úmido.

Cortizo et al. (2008) utilizaram a IRT para o diagnóstico de manifestações patológicas de uma edificação do Patrimônio Histórico Nacional: a Capela São Sebastião de Águas Claras, e concluíram que o ensaio não destrutivo é uma realidade e representa um salto qualitativo na preservação e conservação de bens imóveis históricos, obtendo resultados satisfatórios mesmo quando aplicado em materiais de construção diferentes dos utilizados atualmente, sendo relevante a sua aplicação. Por sua vez, Moresco et al., (2015) testaram o método para detecção de manifestações patológicas em fachadas com revestimento argamassado, como geralmente ocorre em construções atuais, e concluíram que o emprego do método possibilitou a deteç̧ão de áreas com fissuras, biodeterioração da estrutura e manchas, causadas por umidade.

Mais recente, Santos et al. (2019), desenvolveram um estudo experimental como objetivo de analisar a viabilidade da ITR como ferramenta para a deteç̧ão de infiltração em diversos materiais construtivos, e constataram que fatores como a secagem do material e o uso de revestimento impermeável podem afetar a formação de contrastes térmicos entre áreas secas e úmidas, limitando deste modo a eficiência na aplicação da metodologia.

Além da identificação de infiltrações, há necessidade de técnicas não destrutivas para localização de tubulações nas construções, devido à tendência de mudança para sistemas de medição individualizada de água em apartamentos. Alcançar essas adequações requer o uso de um método de identificação de tubulações, visto que a maioria das edificações não mais possui projetos hidráulicos e sanitários.

Al Alam et al. (2016) avaliaram a potencialidade do uso da termografia na detecção das causas de manifestações patológicas associadas à umidade acidental, no entanto, dentro do experimento foi visível a identificação da tubulação embutida em alvenaria em algumas medições. Fato semelhante foi relatado por Santos et al. (2019), que apesar de pesquisar sobre identificação de infiltrações em diversos materiais construtivos, indiretamente possibilitou a identificação de tubulação hidráulica no termograma, quando no ensaio havia sido efetuada a abertura de torneira de água aquecida.

Apesar de ser um tema relevante, estudos diretos sobre identificação de instalações hidro-sanitárias não são encontrados na literatura vigente. Verificada essa lacuna, o objetivo do presente estudo é identificar infiltrações ainda não perceptíveis e investigar o uso de câmeras termográficas e aplicação da IRT para identificação de tubulações de água fria e quente embutidas em alvenarias.

\section{Metodologia}

Para verificar a utilização da termografia infravermelha na detecção de umidade e tentativa de identificação de tubulações embutidas foram realizadas inspeções em ambientes internos e externos em algumas localidades. Segundo Gil (2008). Quanto aos objetivos esta pesquisa pode ser enquadrada como explicativa pois propõe identificar os fatores que determinam ou que contribuem para a ocorrência dos fenômenos, aprofundando o conhecimento da realidade. Também classificada, quanto aos procedimentos técnicos, como uma pesquisa de campo, pois aprofunda então uma realidade específica, com observação direta da situação estudada, sendo então de natureza qualitativa.

A câmera termográfica utilizada para o estudo foi do modelo SAT-G95 com resolução IR de 640x480 (que gera 307200 pixels) além de uma sensibilidade térmica de $\leq 0,1$ a $30^{\circ} \mathrm{C}, 50 / 60 \mathrm{~Hz}$, o que permite dados precisos e imagens nítidas. Para a aplicação da IRT foram escolhidas 4 edificações existentes e ocupadas, com as características apresentadas no Quadro 
1.

Durante as visitas 1 e 2 foi aplicado o método IRT para identificação e confirmação de infiltrações perceptíveis, pouco perceptíveis e não perceptíveis. Nas visitas 3 e 4 a aplicação do método IRT para análise da possibilidade de detecção de tubulações de água fria e quente, em paredes com e sem revestimento cerâmico.

Quadro 1. Visitas realizadas para coleta de dados.

\begin{tabular}{|c|c|c|c|c|c|}
\hline Visita & Data & Horário & $\begin{array}{c}\text { Natureza da } \\
\text { edificação }\end{array}$ & $\begin{array}{c}\text { Aplicação } \\
\text { pretendida }\end{array}$ & Observações \\
\hline 1 & $22 / 01 / 19$ & $14: 00$ & $\begin{array}{c}\text { Residência } \\
\text { unifamiliar }\end{array}$ & $\begin{array}{c}\text { Detecção de } \\
\text { infiltrações }\end{array}$ & $\begin{array}{c}\text { Edificação apresentava } \\
\text { infiltrações em períodos } \\
\text { chuvosos }\end{array}$ \\
\hline 2 & $\begin{array}{c}21 / 01 / 19 \\
\text { e } \\
01 / 04 / 19\end{array}$ & $13: 00$ & $\begin{array}{c}\text { Bloco de aulas } \\
\text { Universidade } \\
\text { Federal da } \\
\text { Paraíba (CTJ) }\end{array}$ & $\begin{array}{c}\text { Detecção de } \\
\text { infiltrações }\end{array}$ & $\begin{array}{c}\text { Apresentava focos } \\
\text { visíveis de infiltrações } \\
\text { em paredes. }\end{array}$ \\
\hline 3 & $25 / 03 / 19$ & $16: 00$ & $\begin{array}{c}\text { Edificação } \\
\text { multifamiliar }\end{array}$ & $\begin{array}{c}\text { Detecção de } \\
\text { tubulação de água } \\
\text { fria }\end{array}$ & $\begin{array}{c}\text { Vistoria em banheiro } \\
\text { com revestimento } \\
\text { cerâmico }\end{array}$ \\
\hline 4 & $16 / 04 / 19$ & $18: 00$ & $\begin{array}{c}\text { Residencial } \\
\text { unifamiliar }\end{array}$ & $\begin{array}{c}\text { Detecção de } \\
\text { tubulação de água } \\
\text { quente }\end{array}$ & $\begin{array}{c}\text { Vistoria em banheiro } \\
\text { com revestimento } \\
\text { cerâmico }\end{array}$ \\
\hline
\end{tabular}

Fonte: Burity Filho (2019).

Para a análise dos resultados, as imagens obtidas foram examinadas tendo como base os contrastes térmicos mostrados, confirmando ou descartando as hipóteses de identificação de infiltrações e tubulações de água fria e quente.

\section{Resultados e Discussão}

Na visita 1 foi aplicada a metodologia IRT em 03 (três) ambientes. Foram identificados pontos que apresentavam infiltrações visíveis (Figura 1) e focos de umidade pouco perceptíveis (Figura 2), os quais foram confirmadas pela aplicação da IRT. Barreira et al. (2016) fizeram experimento em uma parede com aplicação de IRT e aparelho medidor de umidade, o que permitiu leituras confirmadas de presença de umidade, demonstrando que essa metodologia pode detectar áreas úmidas devido à capilaridade e à diferença de temperaturas (mais baixa nas regiões úmidas que as áreas secas), causada pelo fenômeno de evaporação superficial.

Além destes pontos que apresentaram umidade visível, mediante observação da construção, optou-se por efetuar investigação de uma parede que não apresentava sinais visíveis de infiltração, e ao aplicar a metodologia IRT, apresentou como resultados imagens que identificaram uma área úmida não perceptível (Figura 3). Santos et al. (2019), também observaram cenários nos quais imagens convencionais não mostraram com nitidez a diferença entre a porção úmida e a seca da parede com infiltração, mas que os termogramas destacaram essas regiões com clareza, apontando assim a capacidade da termografia na detecção de umidade pouco ou não perceptível. 
Figura 1. Infiltração visível: (A) Situação; (B)Termograma.
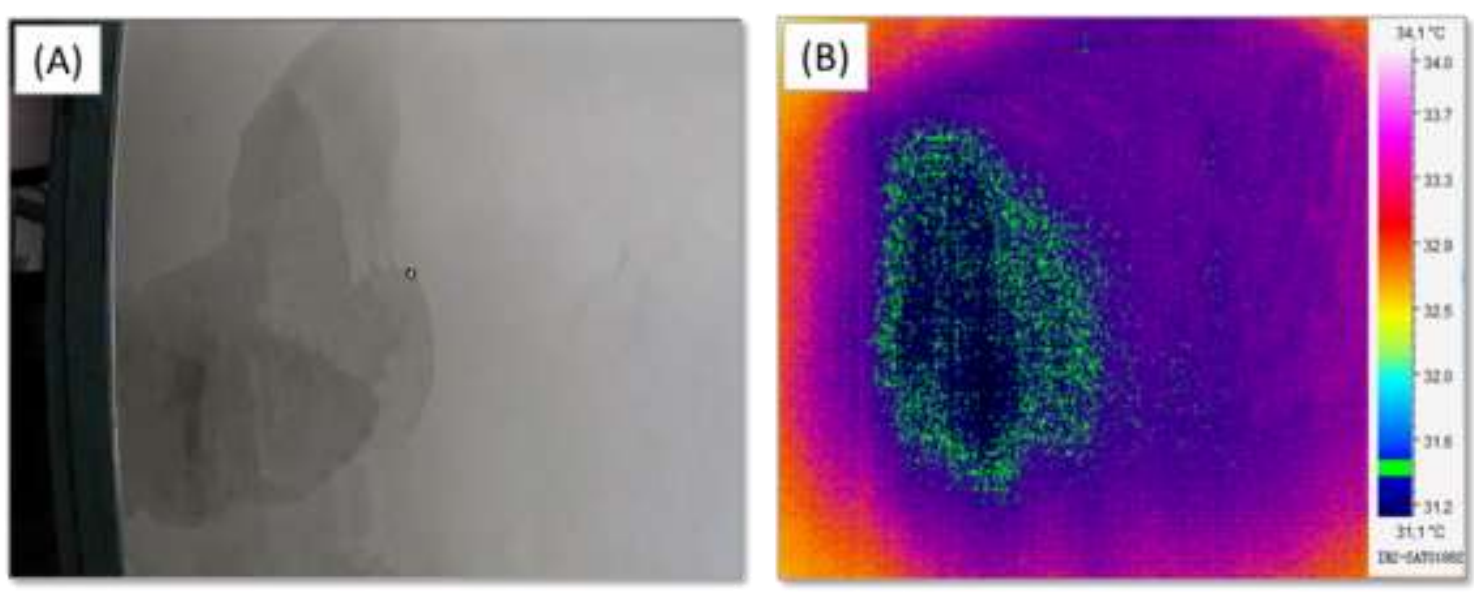

Fonte: Burity Filho (2019).

Figura 2. Infiltração pouco perceptível: (A) Situação; (B) Termograma.

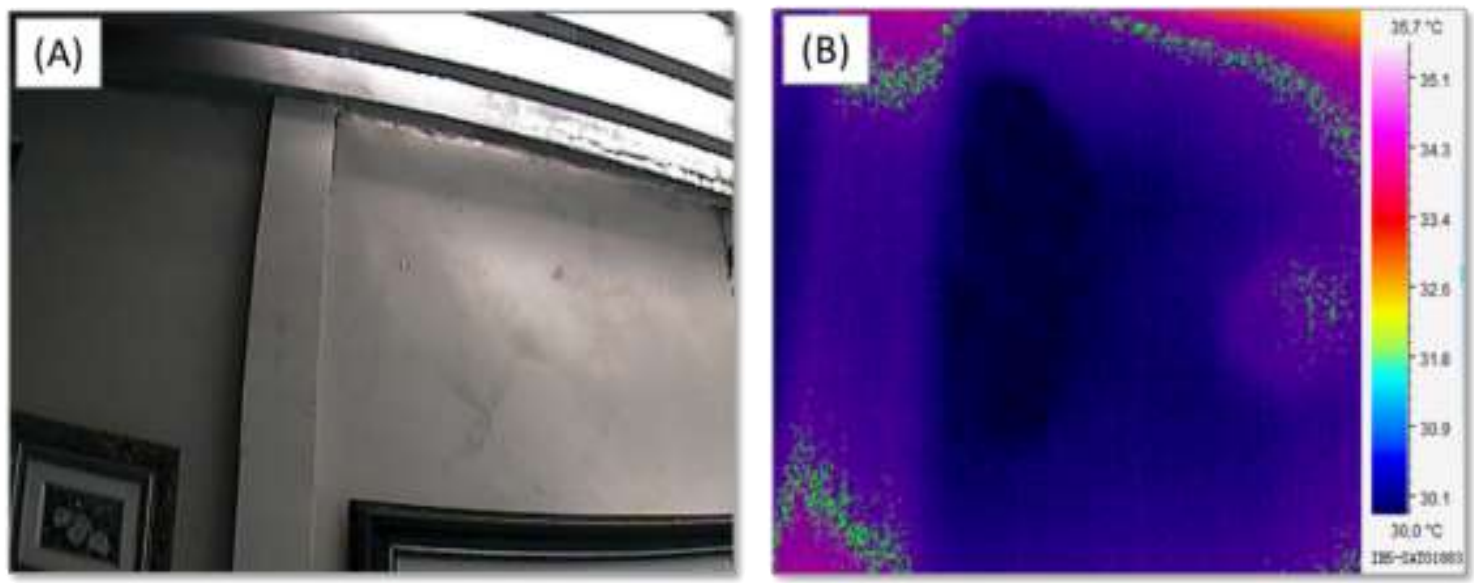

Fonte: Burity Filho (2019).

Figura 3. Identificação de infiltração não perceptível visualmente: (A) Situação; (B) Termograma.
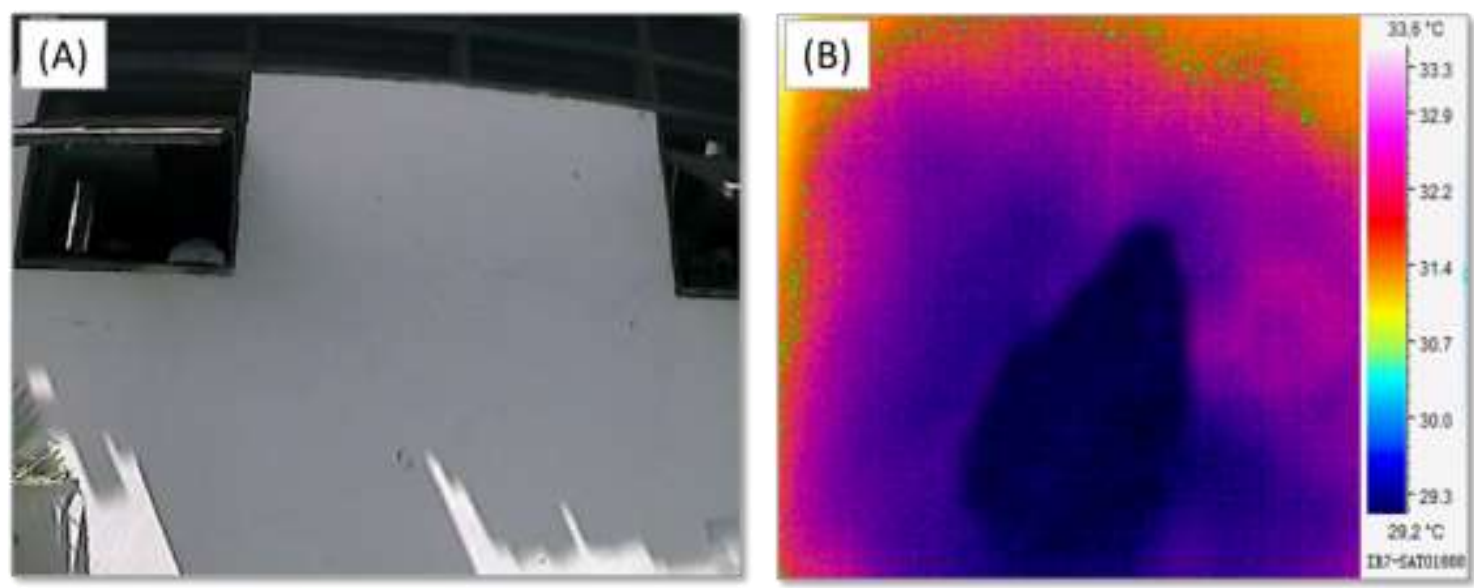

Fonte: Burity Filho (2019).

Barreira et al. (2016) e Al Alam et al. (2016) também verificaram que na fotografia com a câmera tradicional não há indícios de manifestações patológicas, e a parede permanece idêntica ao seu estado original, porém, na imagem termográfica detecta a variação de temperatura decorrente da área úmida. 
A visita 2 foi realizada no bloco de salas de aula da Universidade Federal da Paraíba (UFPB) após longo período de chuvas. A análise termográfica foi aplicada em dois pontos que ainda se apresentavam visivelmente úmidos, com presença de manchas e presença de bolor. A Figura 4 e Figura 5 apresentam termogramas que confirmaram a presença de umidade visível, decorrentes do período de chuva precedente à análise.

Figura 4. Identificação de infiltração pouco perceptível visualmente localizado no bloco CTJ /UFPB.
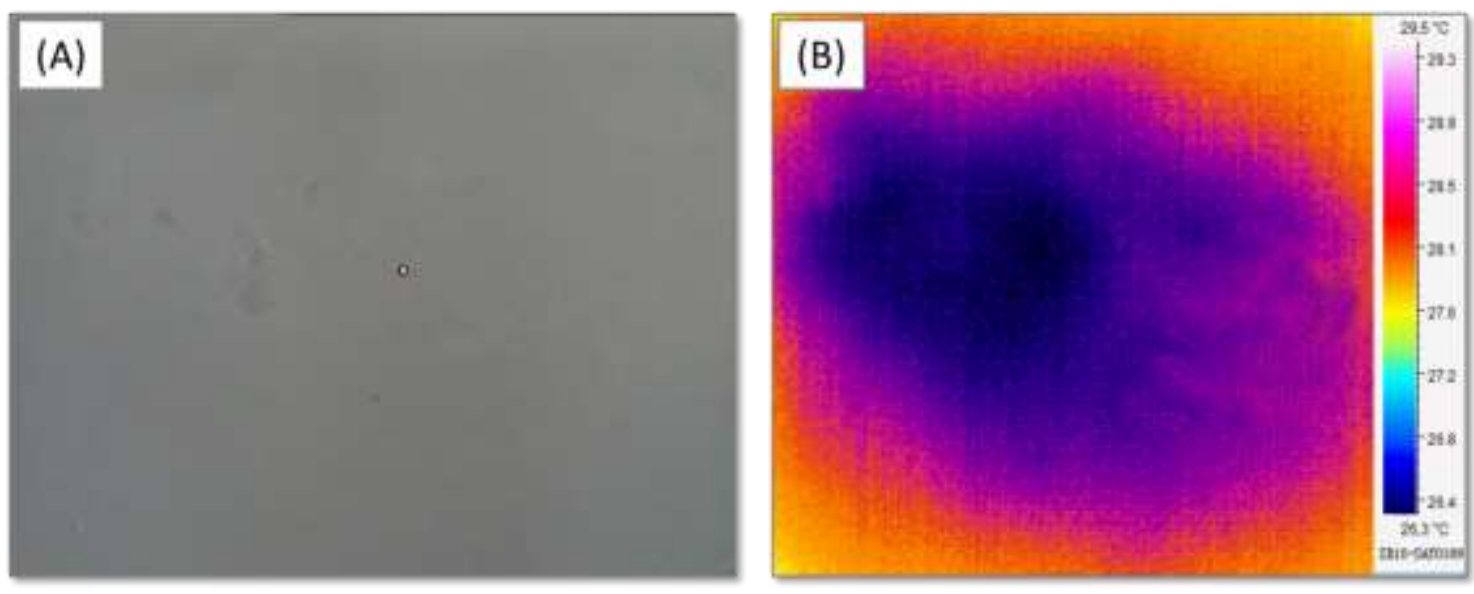

Fonte: Burity Filho (2019).

Figura 5. Identificação de infiltração em sala localizada no bloco CTJ / UFPB.

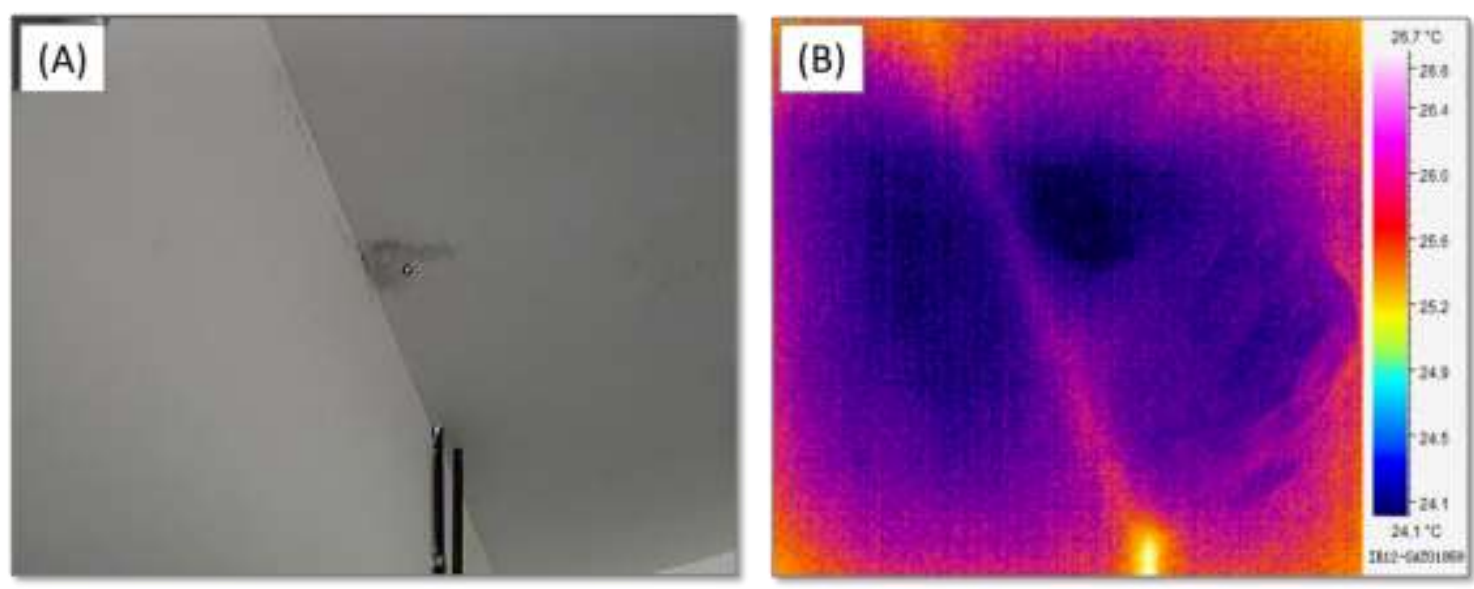

Fonte: Burity Filho (2019).

As visitas 3 e 4 tiveram como objetivo verificar a possibilidade de utilização do método da IRT para tentativa de identificação de tubulações hidráulicas embutidas em alvenaria com revestimento simples e cerâmico.

Na visita 3 houve a tentativa de identificação das tubulações de água mediante a aplicação da IRT após abertura da torneira, tanto na parede interna do banheiro dotada de revestimento cerâmico, quanto na parede externa dotada de revestimento simples.

A termografia demonstrou que o revestimento cerâmico presente na parede interna não permite a visualização da tubulação embutida na alvenaria, e o que aparentava ser uma indicação de tubulação interna, é na verdade apenas comportamento distinto do material componente do rejunte utilizado (Figura 6). 
Figura 6. Imagem termográfica de tubulação frente a cerâmica apresentando reflexão.
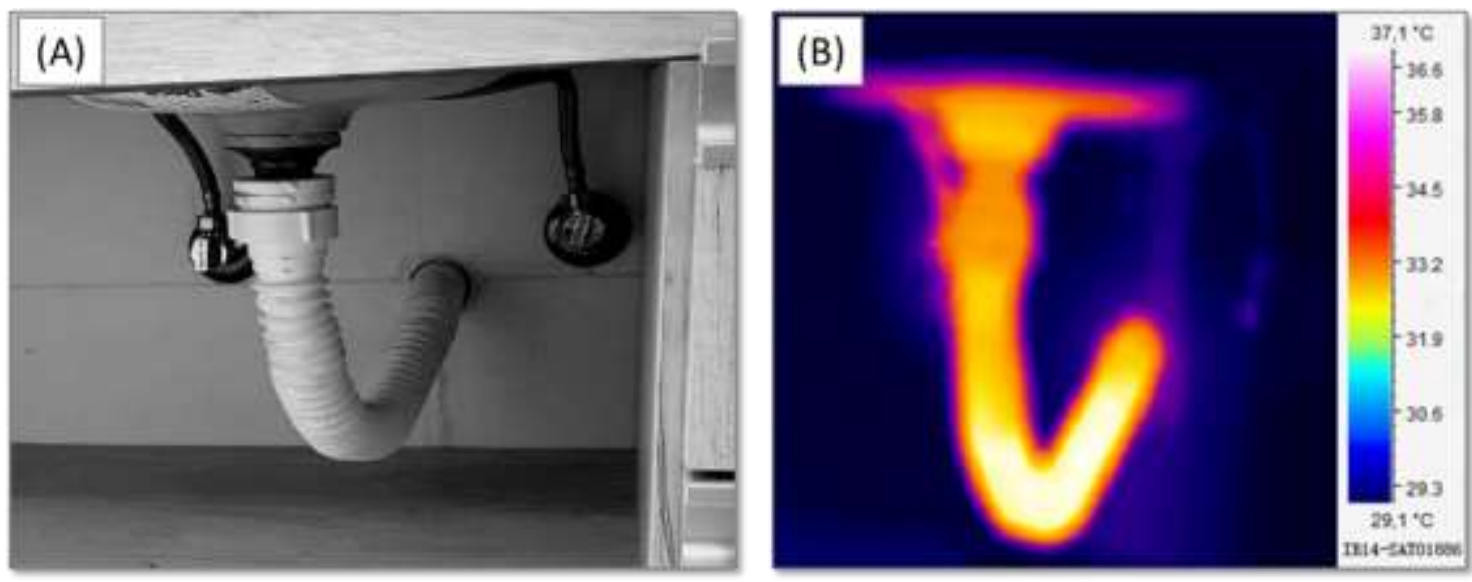

Fonte: Burity Filho (2019).

A literatura que aborda o comportamento de revestimentos cerâmicos quando submetidos a metodologia da termografia é apenas voltada para a identificação de infiltrações e presença de umidades na parede, ou para estudo de conforto térmico, o que está distante dos objetivos deste estudo. No entanto, tais autores fornecem informações importantes para analisarmos os resultados deste trabalho.

Segundo Barreira (2004) e Barreira e Freitas (2007), os materiais cerâmicos têm características peculiares (propriedades refratárias, capacidade térmica, por exemplo) e por isso necessitam de um período de contato maior para que haja mudança de sua temperatura. Tal fato pode justificar a ausência de resposta na termografia devido ao acionamento por curto período da água, que pode não ser o suficiente para gerar um gradiente térmico significativo e detectável.

Rocha et al. (2018) e Santos et al. (2019), apesar de terem verificado ser possível a identificação de infiltrações mesmo em paredes com revestimento cerâmico, citam que este revestimento pode impedir que a radiação emitida pela parede seja captada de forma direta pela câmera, diminuindo assim os gradientes térmicos captados. Ou seja, por estes estudos pode-se verificar que presença do revestimento cerâmico impossibilita ou dificulta a detecção da radiação térmica da parede, dificultando a utilização adequada da metodologia IRT para investigar tais fenômenos no interior de alvenaria revestida por cerâmica.

Também foi efetuada observação do lado externo do banheiro, com revestimento simples de argamassa e pintura, onde se sabia que passava a tubulação do chuveiro. Ligou-se o chuveiro (apenas água fria) para apresentar uma situação de água corrente, porém o termograma não apresentou variações de temperaturas que mostrassem a localização precisa da tubulação (Figura 7), ou seja, não foi formado gradiente de temperatura suficiente entre a tubulação e a alvenaria detectável pelo método. 
Figura 7. Tentativa de detecção de tubulação de água fria embutida em alvenaria.

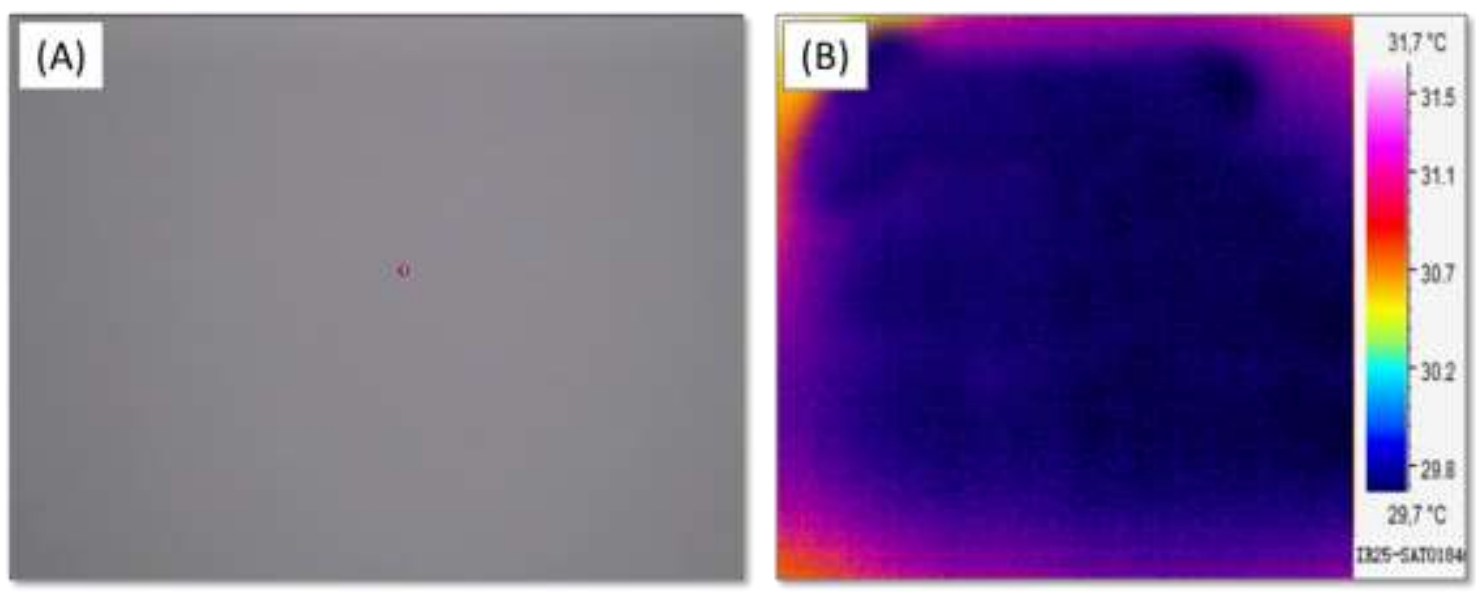

Fonte: Burity Filho (2019).

Por sua vez, a visita 4 ocorreu em uma residência unifamiliar provida de um aquecedor solar que armazena a água aquecida em um boiler, com condução feita por tubulações de CPVC (policloreto de vinila clorado). Foi investigada a possibilidade de identificar a tubulação de água quente, uma vez que esta poderia gerar gradientes de temperatura maiores entre as tubulações e a parede.

A aplicação do método IRT realizada na face interna da parede do chuveiro, que apresentava revestimento cerâmico, iniciou-se após alguns instantes da abertura do registro de água quente. Assim como observado na visita 3, em parede revestida de cerâmica não foi possível identificar a tubulação embutida, mesmo com a aplicação da água quente.

Apesar da elevada temperatura da água, não houve a criação de um gradiente de temperatura suficiente para ser detectado pela câmera termográfica. Como explicado por Rocha et al. (2018), a radiação emitida pela superfície da parede é transferida para a placa, o que afeta a temperatura desta. A câmera capta a radiação emitida pela placa e, consequentemente, os diferenciais de temperatura, que pela presença da cerâmica, são menores.

Porém, ao aplicar a metodologia na face externa da parede do chuveiro, que apresentava revestimento simples de argamassa e pintura, foi possível observar no termograma (Figura 8) um gradiente de temperatura que mostra com precisão a localização da tubulação, em coloração alaranjada. Neste caso, a confirmação foi dada uma vez que era conhecida a localização da tubulação condutora de água quente.

A falta de estudos acerca da detecção de tubulações embutidas dificulta a análise deste comportamento, no entanto os resultados advindos de Santos et al. (2019) auxiliam no entendimento de que, água aquecida após certo tempo de aplicação (a partir de 5 minutos com o pico em 40 minutos) pode gerar gradientes de temperatura significativos, devido à maior emissão de radiação na região na alvenaria, mudando a inércia térmica do material de revestimento simples.

A aplicação da água quente então torna-se o diferencial para metodologia, bem como em Glavas et al. (2019) que ao analisarem elementos embutidos em alvenarias em construções históricas efetuaram o uso de fonte de calor externa para auxiliar na formação desse gradiente de temperatura e otimização da IRT, ou seja, usaram a termografia ativa para assim identificar objetos embutidos. 
Figura 8. Identificação de tubulação de água quente embutida em alvenaria.

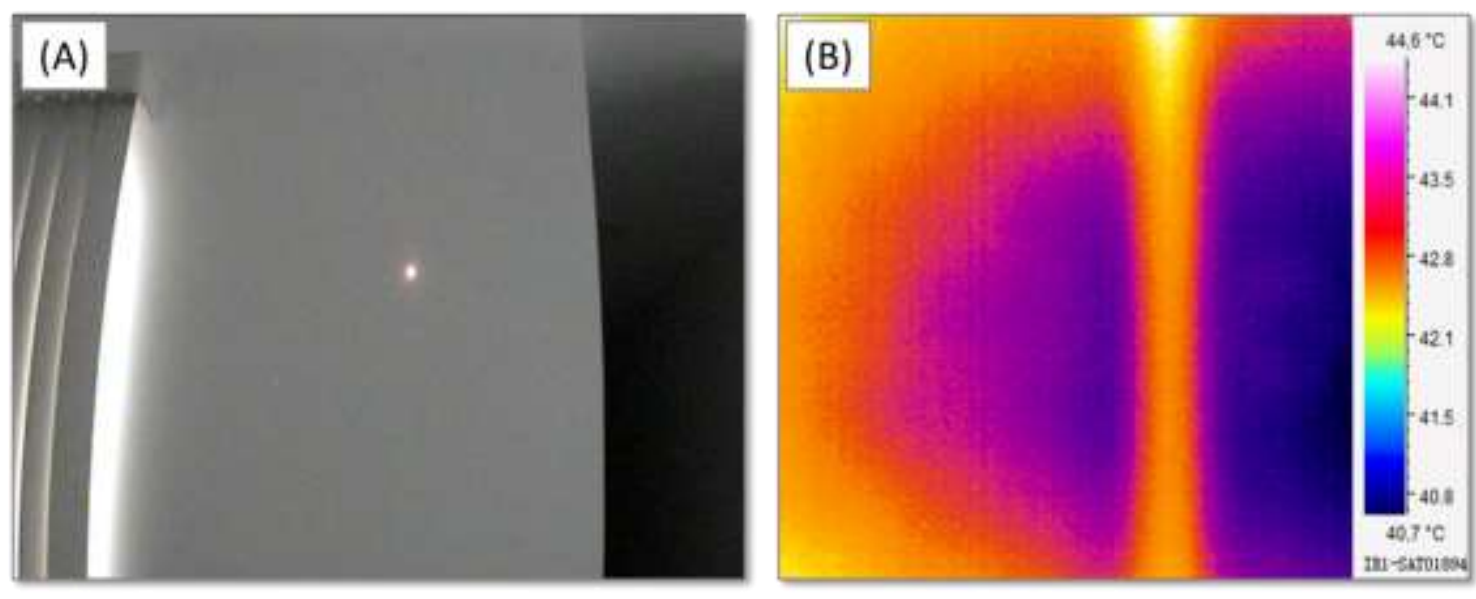

Fonte: Burity Filho (2019).

Outro trabalho que enfatizou a vantajosa aplicação da termografia ativa foi o de Lerma et al. (2018), no qual os autores concluíram que apesar de ser possível a aplicação da IRT passiva na detecção de vazamentos de ar, o uso de IRT ativa propicia resultados mais claros em termos de imagens térmicas.

A metodologia IRT é subutilizada para a identificação de objetos embutidos na alvenaria, inclusive as tubulações hidráulicas uma vez que grande maioria das paredes que apresentam tubulações hidráulicas embutidas são dotadas de revestimento cerâmico como é o caso de banheiros, cozinhas e áreas de serviço. Como o foi demonstrado por este e demais estudos, esse tipo de revestimento é considerado um objeto que impede a medição direta, e isso tem influência nos resultados da ITR (Rocha et al., 2018), o que pode ser uma limitação para a utilização da metodologia na detecção destas tubulações.

No entanto, ao investigar paredes com revestimento de argamassa e tinta, a detecção das tubulações hidráulicas só irá ocorrer caso haja gradiente de temperatura entre a tubulação e a parede suficientes para detecção. De modo que para deteção de tubulações de água fria, não foi possível por meio da termografia esta identificação. Por outro lado, para tubulações de água quente a detecção foi verificada nos termogramas, pois houve significativo gradiente de temperatura, advindo da água aquecida. Portanto, a utilização dessa fonte de calor tornou a técnica passível de aplicação para este fim.

\section{Conclusão}

Diante dos resultados, conclui-se que a análise termográfica se apresentou adequada para a deteç̧ão de infiltrações, sejam estas perceptíveis ou não, fornecendo mais informações que uma inspeção à olho nu.

A identificação de tubulações hidráulicas embutidas nas paredes com revestimento cerâmico apresentou a limitação pelo método IRT devido ao revestimento ser um objeto que impede/dificulta a medição direta das temperaturas internas a ele. Portanto, os termogramas não apresentaram gradientes de temperatura suficientes para esta identificação.

A determinação da localização de tubulações hidráulicas embutidas em paredes com revestimento simples (argamassa + tinta) apenas obteve resultados positivos para aplicação da IRT após utilização de água quente, visto que a elevada temperatura da água promove um aumento do gradiente de temperatura entre a tubulação e a parede, e com isso é percebida pelo método.

Deste modo, os resultados obtidos permitem apontar a potencialidade da termografia (ou IRT) para deteç̧ão de infiltrações e tubulações hidráulicas de água quente, mas não justifica sua aplicação para detecção de tubulações hidráulicas condutoras de água fria.

Para resultados mais amplos, trabalhos futuros devem ser efetuados investigando diferentes tempos de contato da água 
quente com as tubulações e alvenarias adjacentes, para verificar se há respostas diferentes da aplicação da termografia. Buscando assim entender mais profundamente os efeitos da água quente como elemento auxiliar na identificação de tubulações embutidas.

\section{Agradecimentos}

Os autores agradecem ao Laboratório de Tecnologia de Novos Materiais - TECNOM (IDEP-UFPB), nas pessoas dos professores Sandro Marden Torres e Antônio Farias Leal, pelo empréstimo da câmara termográfica para realização deste trabalho.

\section{Referências}

Al Alam, F. W., Pinz, F. P., Torres, A. S. \& Paliga, C. M. (2016). Potencial da termografia infravermelha na detecção de manifestações patológicas ocultas ocasionadas pela umidade acidental em paredes de alvenarias cerâmicas com revestimento de argamassa e pintura. Revista de Arquitetura IMED, 5(1), 28-47. https://doi.org/10.18256/2318-1109/arqimed.v5n1p28-47

Almeida, A. S. F. C., Ornelas, A. \& Cordeiro, A. M. R. (2020). Termografia passiva no diagnóstico de patologias e desempenho térmico em fachadas de edifícios através de câmara térmica instalada em drone. Abordagem preliminar em Coimbra (Portugal). Cadernos de Geografia n ${ }^{\circ} 42$, Coimbra, FLUC. 2, $27-$ 41. https://dx.doi.org/10.14195/0871-1623_42_2

Associação Brasileira de Normas Técnicas - ABNT (2020). NBR 16818: Ensaios não destrutivos - Termografia infravermelha - Procedimentos para aplicações do método da termografia infravermelha. Rio de Janeiro.

Barreira, E. \& Freitas, V. P. de. (2007). Evaluation of building materials using infrared thermography. Construction and Building Materials, 21 (1), 218-224. 10.1016/j.conbuildmat.2005.06.049

Barreira, E., Almeida, R. M. S. F. \& Delgado, J. M. P. Q. (2016). Infrared thermography for assessing moisture related phenomena in building components. Construction and Building Materials, 110 (1), 251-269. https://doi.org/10.1016/j.conbuildmat.2016.02.026

Barreira, E. S. B. M. (2004). Aplicação da termografia ao estudo do comportamento higrotérmico dos edifícios. Dissertação (Mestrado) - Faculdade de Engenharia, Universidade do Porto, Porto.

Burity Filho, R.L. (2019). Aplicação da termografia na identificação de infiltrações e tubulações para condução de água fria e água quente embutidas em alvenaria. Trabalho de conclusão de curso (Engenharia civil) - Universidade Federal da Paraíba, Paraíba, Brasil.

Cortizo, E. C., Barbosa, M. P. \& Souza, L. A. C. Estado da Arte da Termografia. Revista Ambiente Contruído. 2(2), $158-193$.

Edis, E., Flores-Colen, I., \& Brito, J. de (2014). Passive Thermographic Detection of Moisture Problems in Façades With Adhered Ceramic Cladding. Construction and Building Materials, 51, 187-197. https://doi.org/10.1016/j.conbuildmat.2013.10.085

Freitas, J. G. de, Carasek, H., Cascudo, O. (2014). Utilização de termografia infravermelha para avaliação de fissuras em fachadas com revestimento de argamassa e pintura. Ambiente Construído, 14(1), 57-73. https://doi.org/10.1590/S1678-86212014000100006

Garrido, I. Lagüela, S. \& Arias, P. (2018). Infrared Thermography's Application to Infrastructure Inspections. Infrastructures, 35(3). 10.3390/infrastructures3030035

Gil, A. C. (2008). Como elaborar projetos de pesquisa. (4a ed.), Atlas.

Glavaš, H., Hadzima-Nyarko, M., Buljan, I. H., \& Barić, T. (2019) Locating hidden elements in walls of cultural heritage buildings by using infrared thermography. Buildings, 9(2), 20. https://doi.org/10.3390/buildings9020032

Kersul, G. M. (2015) Uso da termografia para inspeções e manutenção predial-estudo de caso. Trabalho de conclusão de curso (Engenharia Civil). FATECS/UNICEUBS, Brasília, Brasil.

Lerma, C., Barreira, E. \& Almeida, R. M. S. F. (2018). A discussion concerning active infrared thermography in the evaluation of buildings air infiltratio. Energy and Buildings, 168 (1), 56-66. https://doi.org/10.1016/j.enbuild.2018.02.050

Moresco, J., Bordin, F., Veronez, M. \& Kulakowski, M. P. (2015). Termografia Infravermelha na detecção de manifestações patológicas em fachadas com revestimento argamassado. Anais XXI Congresso Internacional sobre Patologia e Recuperação de Estruturas - São Leopoldo.

Rocha, J. H. A. \& Póvoas, Y. V. (2017). A termografia infravermelha como um ensaio não destrutivo para a inspeção de pontes de concreto armado: Revisão do estado da arte. Revista ALCONPAT, 7 (3). https://doi.org/10.21041/ra.v7i3.223

Rocha, J. H. A., Santos, C. F. dos, Oliveira, J. B. de, Albuquerque, L. K. dos S., Póvoas, Y. V. (2018) Detecção de infiltração em áreas internas de edificações com termografia infravermelha: estudo de caso. Ambiente Construído, 18(4), 329-340. http://dx.doi.org/10.1590/s1678-86212018000400308

Santos, L. (2012) Classificação e modelagem de fatores de influência sobre inspeções termográficas em ambientes desabrigados. Tese (Doutorado) Universidade Federal de Itajubá, Itajubá, Minas Gerais, Brasil. 
Research, Society and Development, v. 10, n. 8, e34610817480, 2021

(CC BY 4.0) | ISSN 2525-3409 | DOI: http://dx.doi.org/10.33448/rsd-v10i8.17480

Santos, C. F. dos, Rocha, J. H. A., Póvoas, Y. V. (2019) Utilização da termografia infravermelha para detecção de focos de umidade em paredes internas de edificações. Ambiente Construído, 19(1), 105-127. http://dx.doi.org/10.1590/s1678-86212019000100296

Silva, R. N. T. da. Estudo da termografia por infravermelho: aplicações na engenharia e determinação de parâmetros termofísicos e geométricos de materiais (2007). Dissertação (Mestrado) - Universidade Federal de Pernambuco, Recife, Pernambuco, Brasil. 